\title{
A IDÉIA DE AUTONOMIA DO INDIVÍDUO EM AMY \\ GUTMANN E A IDÉIA DO SUJEITO EM ALAIN TOURAINE $^{1}$
}

\section{Dora Maria Farias Lopes}

Mestre em Sociologia Política.

\begin{abstract}
SUMÁRIO: Introdução; 1 A Democracia Deliberativa e a Autonomia dos Indivíduos em Amy Gutmann; 2 A Concepção do Sujeito em Alain Touraine; 3 Considerações sobre a Autonomia do Indivíduo em Gutmann e Touraine; À Guisa de Conclusão; Referências Bibliográficas.
\end{abstract}

\section{INTRODUÇÃO}

A proposta deste trabalho é examinar se a idéia de autonomia do indivíduo de GUTMANN e a idéia do sujeito de TOURAINE são concepções semelhantes. Ambos os autores expressam a autodeterminação dos indivíduos como condição necessária da democracia, articulando, num espaço público institucional, atores, sujeitos de sua história e condutores de sua vida pública e privada. O sujeito de TOURAINE é a expressão sociológica do cidadão que experimenta autonomia?

“... Sempre que, pelo contrário, uma coletividade afirma o seu direito à autodeterminação e a capacidade de tomar nas mãos os seus próprios assuntos, o que supõe a existência de opções possíveis, a democracia está presente e se reforça.

Não se trata aqui apenas de respeitar e proteger a liberdade negativa. A democracia necessita de vontade ativa de libertação e da confiança na capacidade coletiva de ação. Pois não se pode separar liberdade e responsabilidade. Não há democracia se os governantes não prestam contas ao povo e se não se submetem simultaneamente à decisão dos eleitores e ao julgamento da lei." (TOURAINE, 1998, p. 293)

"A democracia deliberativa propõe a resposta de que valorizamos a vontade popular e a liberdade pessoal na medida em que o exercício de uma e outra reflitam ou exprimam a autonomia das pessoas, entendendo-se autonomia como autodeterminação, isto é, a disposição e a capacidade de determinar os rumos da própria vida privada ou pública por meio da deliberação, da reflexão informada, do julgamento e da persuasão que alia a retórica à razão." (GUTMANN, 1995, p. 20)

1 Artigo de conclusão da disciplina Teoria Política Contemporânea - Mestrado da Universidade Federal de Santa Catarina - 1998/2000. 


\section{A DEMOCRACIA DELIBERATIVA E A AUTONOMIA DOS INDIVÍDUOS EM AMY GUTMANN}

AMY GUTMANN examina o ideal de democracia, tentando reconciliar as oposições entre a democracia populista e o liberalismo.

A democracia populista tem seu centro na exigência de liberdades de expressão, de imprensa, de associação, no direito de não sofrer prisão arbitrária, no direito de formação de partidos e no direito ao voto, em eleições.

Acresce-se a isso que o ideal da democracia populista é a valorização da vontade da maioria, expressa nas eleições.

O liberalismo, por sua vez, tem como valor dominante, enquanto doutrina, a garantia das condições que são necessárias ao exercício da liberdade pessoal. O liberalismo é protetor da liberdade, aquela liberdade de não sofrer interferências na vida pessoal (liberdade negativa).

A democracia deliberativa oferece uma proposta que une a importância da tomada de decisões pela maioria e a importância da liberdade pessoal.

Conforme o parágrafo citado na introdução deste trabalho, o núcleo da democracia deliberativa está no valor primordial de encorajar a deliberação e expressão das pessoas sobre as várias dimensões de sua vida.

A liberdade pessoal será potencializada na medida em que se constituir em autonomia para refletir, julgar e decidir, coletivamente, questões que sejam de interesse particular ou comum à comunidade.

Nesse ponto GUTMANN acrescenta a importância da argumentação persuasiva, que é "a forma mais defensável de poder político porque é a mais consistente com respeito a autonomia das pessoas, à capacidade que elas tem de autodeterminação"(GUTMANN, 1995, p. 21).

O desenvolvimento da autonomia requer instituições e práticas políticas que a garantam e encorajem os indivíduos à participação. Aqui a questão não se refere à autonomia individualista e sim a sua dimensão de natureza política, ou seja, "exige que as autoridades que tomam decisões que influenciam e restringem as escolhas dos cidadãos prestem contas a nós" (GUTMANN, 1995, p. 23).

Para GUTMANN a chave da democracia deliberativa não está centrada na participação direta, mas na necessidade das autoridades (representantes) prestarem contas de seus atos (accountability). Se a autonomia tem como pressuposto a deliberação, a democracia desse tipo exige uma contínua prestação de contas daqueles que tomam decisões. Para isso, não se pode prescindir de instituições que garantam esse processo e possibilitem a participação e a discussão dos indivíduos sobre as questões públicas. Do contrário, "os membros de uma sociedade não são politicamente livres, e a falta de liberdade política diminui sua liberdade pessoal de uma forma direta e palpável" (GUTMANN, 1995, p. 30). 
A democracia deliberativa, como teoria política e moral substantiva, não pressupõe que sempre haverá convergência de opiniões e soluções únicas para problemas políticos que se coloquem.

O mais importante é o indivíduo ter espaço no processo de deliberação, que a autonomia não seja violada pelo fato de outros decidirem entre valores conflitantes, em nome da comunidade, sem a contrapartida da prestação de contas pública.

“... A democracia deliberativa procura maximizar o escopo da autodeterminação para indivíduos interdependentes e sustentar os processos políticos que ampliam a capacidade dos indivíduos de tomar decisões informadas sobre suas vidas. Autonomia qualifica o valor tanto da liberdade pessoal quanto do governo da maioria para torná-los compatíveis entre si, tendo essa acomodação o objetivo de capacitar as pessoas a governar suas vidas de forma deliberativa, e não de acordo com algum plano superior ou segundo o julgamento de um intelecto filosófico superior ou da autoridade política."(GUTMANN, 1995, p. 34)

\section{A CONCEPÇÃO DO SUJEITO DE ALAIN TOURAINE}

TOURAINE, na apresentação de seu livro $O$ que é a democracia, expressa a busca da rearticulação entre a racionalização e a subjetivação.

A racionalização do mundo moderno está reduzindo os indivíduos a meros consumidores, tanto de produtos econômicos como políticos, e a subjetivação, como afirmação da identidade e da liberdade individual transforma-se em nacionalismos intolerantes e irracionais.

Para recompor este mundo dividido, TOURAINE se apóia na idéia do sujeito:

"Tal reconstrução deve ser feita, primeiramente, no âmbito do ator social concreto, indivíduo ou grupo, pela combinação entre razão instrumental, indispensável em um mundo de técnicas e permutas, e a memória ou imaginação criadora, sem as quais não existem atores para produzirem a história, mas somente agentes produtores de uma ordem fechada sobre si mesma. Optei por definir o sujeito como o esforço de integração dessas duas faces da ação social." (TOURAINE, 1996, p. 11)

A modernização não pode continuar a lutar contra o sujeito, que é parte intrínseca de si mesma, não pode reduzir o sujeito à própria razão.

TOURAINE afirma que:

"O mundo moderno é, ao contrário, cada vez mais ocupado pela referência a um Sujeito que está libertado, isto é, que coloca como princípio do bem o controle que o indivíduo exerce sobre suas ações e sua situação e que lhe permite conceber e sentir seus comportamentos como componentes da sua história pessoal de vida, conceber a si mesmo como ator. O Sujeito é a vontade de um indivíduo de agir e de ser reconhecido como ator."(Touraine, 1994, p. 219) 
É importante ressaltar que a efetivação do Sujeito não se realiza individualmente mas nas relações que desenvolve com outros indivíduos "... o sujeito se constrói simultaneamente, pela luta contra os aparelhos e pelo respeito do outro como sujeito" (TOURAINE, 1994, p.302).

Nesse momento TOURAINE alinha Sujeito e participação social "Não existe sujeito sem engajamento social", pois é nela que o indivíduo vai opor resistência à lógica dominadora dos sistemas, reafirmando seus particularismos e seu desejo de liberdade.

Para TOURAINE é a democracia que deve fornecer as condições e garantias para a ação do sujeito e, por isso, não pode ser resumida a uma concepção de procedimentos institucionais, "deve ajudar os indivíduos a serem sujeitos e conseguirem em si mesmos, através de suas práticas como de suas representações, a integração não só de sua racionalidade, isto é, sua capacidade de manipular técnicas e linguagem, mas também de sua identidade que se apóia em uma cultura e tradição, reinterpretada constantemente por eles em função das transformações do meio técnico"(TOURAINE, 1996, p. 175).

Portanto, a democracia é a organização que vai possibilitar a integração entre racionalidade e identidade e vai mediar o Estado e a sociedade civil.

TOURAINE vê a necessidade de reconstrução da democracia baseada em um sistema político que se afasta do Estado e que caminha para reforçar as associações e os movimentos culturais, forçando o restabelecimento do processo de encaminhamento das reivindicações sociais ao campo político. político.

A ação democrática se efetuará de baixo para cima, dos atores para o sistema

"A democracia se desloca para a base: da relação entre o estado e o sistema político ela se desloca para a relação do sistema político e dos atores sociais. Ela havia criado a cidadania acima de uma sociedade civil fragmentada e hierarquizada. Hoje, defende a diversidade dos atores, das culturas, das associações, das minorias e, de maneira mais central, a liberdade que repousa numa sociedade plural e mutável, no reconhecimento do outro como sujeito." (TOURAINE, 1999, p. 289)

Retomando o parágrafo citado na introdução deste trabalho, a democracia hoje está presente, quando os indivíduos passam a ser sujeitos e quando a sociedade está assentada nos movimentos sociais, nas associações e na opinião pública. A democracia passa pela liberdade, indissociável da responsabilidade dos atores sociais, confiantes na capacidade de suas ações.

\section{CONSIDERAÇÕES SOBRE A AUTONOMIA DO INDIVÍDUO EM GUTMANN E TOURAINE}

A princípio, é importante salientar que, embora os dois autores tratem da questão da autonomia dos indivíduos, GUTMANN expõem uma teoria política que ressalta a 
importância do sistema: democracia deliberativa como modo de ser do processo político. Seu olhar tem como ponto de partida as transformações que são necessárias no campo político para que o sistema responda melhor às divergências que se apresentam no relacionamento da democracia populista, que dá importância primordial à tomada de decisões da maioria, e o liberalismo que tem como núcleo fundamental a maior liberdade possível dos cidadãos.

TOURAINE, ao contrário, aborda a autonomia dos indivíduos com um olhar sociológico, buscando no Sujeito - "vontade de um indivíduo de agir e ser reconhecido como ator", a rearticulação, na sociedade, dos elementos que foram divididos pela modernidade, a racionalidade e a individualidade.

É no ator, individual ou coletivo, que TOURAINE diz se operar a combinação entre o universal e o particular, e é no campo institucional que estão as condições indispensáveis para a ação do sujeito. Esta se dá nas relações que os indivíduos desenvolvem com outros sujeitos, na luta contra a lógica dominadora dos sistemas.

Assim, para ambos os autores, a democracia deve fornecer as condições, procedimentos institucionais, que garantam a autonomia dos indivíduos, a autodeterminação para conduzir suas vidas públicas ou privadas.

Entretanto, os autores também afirmam que a democracia não é somente um conjunto de garantias institucionais, não pode ser resumida a instrumentalidade, mas garantir efetivamente a autonomia dos cidadãos em GUTMANN e garantir a ação dos sujeitos em TOURAINE.

TOURAINE afirma que a democracia é o regime político que "permite aos atores sociais formar-se e agir livremente" (TOURAINE, 1994, p. 345). Para tanto, três princípios devem estar presentes na ordem das instituições políticas:

1. O reconhecimento dos direitos fundamentais que limitam o poder do Estado - liberdades negativas;

2. A representatividade social dos dirigentes e de sua política, que expressam a pluralidade dos interesses dos indivíduos; e

3. A consciência da cidadania - desejo de pertença a uma sociedade política e sentir-se responsável pelo funcionamento das instituições.

Princípios paralelos estão no pensamento de AMY GUTMANN quando faz a crítica da democracia populista e do liberalismo, para recompor, ao final, sob o termo democracia deliberativa, uma acomodação entre os valores essenciais das liberdades pessoais (princípio primeiro de TOURAINE) e a necessidade de representantes que efetivamente expressem o interesse dos atores sociais (princípio segundo de TOURAINE).

Nesse ponto, GUTMANN ressalta que a garantia do reconhecimento público do status político dos cidadãos está na relação que mantém com os representantes, na prestação de contas (accountability), que é exigida daqueles que representam a comunidade. 
TOURAINE expressa essa idéia quando diz que "não há democracia se os governantes não prestam contas ao povo e não se submetem simultaneamente à decisão dos eleitores e ao julgamento da lei" (TOURAINE, 1998, p. 293).

Com relação ao terceiro princípio, a cidadania, TOURAINE vai além daquele sentido restrito do direito de voz e voto, ampliando-o com a inclusão da consciência de pertença a uma coletividade política, como responsabilidade de cada um na organização da vida social.

Quando GUTMANN identifica a autonomia com a autodeterminação, como exigência de práticas deliberativas, isto é, envolvimento nas decisões políticas, expressa a idéia de cidadania de TOURAINE, em que a participação é fundamental para a democracia.

TOURAINE afirma que o reconhecimento da existência de conflitos de valores em uma sociedade é base para a existência de uma democracia e o funcionamento de seu processo político. É esse que deve salvaguardar a diversidade através da organização de um espaço de debates que possibilite deliberações políticas. "Atualmente a democracia é o meio político de salvaguardar essa diversidade, fazer viver um conjunto de indivíduos e grupos cada vez mais diferentes uns dos outros, em uma sociedade que também deve funcionar como uma unidade" (TOURAINE, 1996, p. 165).

GUTMANN também se refere à existência de valores conflitantes em uma sociedade e que é impossível à democracia encontrar soluções indisputadas. O que é necessário é que as pessoas "aprendam a respeitar uns aos outros como seres, não somente voluntariosos ou egoístas, mas também deliberantes" (GUTMANN, 1995, p. 28).

\section{À GUISA DE CONCLUSÃO}

O Sujeito de TOURAINE, aquele que expressa vontade de agir e ser reconhecido como ator, se forma no seu envolvimento nos processos sociais, na relação com outros indivíduos contra aquela democracia que reduz o sistema político a um mercado político.

O autor define democracia como uma determinada forma de organização que deve permitir a expressão do indivíduo ou grupo e o debate político institucionalmente aberto.

Esse sujeito de TOURAINE pode ser identificado com o cidadão que experimenta autonomia, conforme conceito de AMY GUTMANN, na medida em que a autora, ao criticar a democracia norte-americana, que evita a reflexão dos cidadãos sobre questões públicas, propõe que se valorize a vontade popular e a liberdade pessoal, através do exercício da autonomia, da autodeterminação para refletir e decidir, coletivamente, questões de interesse comum à comunidade.

Todavia, parece importante lembrar que TOURAINE, quando define democracia, estende seu conceito para além das instituições e modos de funcionamento do sistema, incluindo "O respeito pelos projetos individuais e coletivos, que combinam a afirmação de uma liberdade pessoal com o direito de identificação com uma coletividade social, 
nacional ou religiosa particular. A democracia não se apóia somente nas leis, mas sobretudo em uma cultura política"(TOURAINE, 1994, p. 26).

TOURAINE está preocupado com uma cultura política democrática que combine unidade e diversidade, que combine o cidadão e o respeito às diferenças individuais.

Nesse sentido, o conceito de sujeito de TOURAINE se insere numa perspectiva teórica maior do que a abrangida pelo conceito correspondente de GUTMANN. Isso, entretanto, ultrapassa a ambição deste trabalho.

\section{REFERÊNCIAS BIBLIOGRÁFICAS}

GUTMANN, Amy. A desarmonia da democracia. In: Lua Nova, n. 36, 1995, p. 05-47.

TOURAINE, Alain. Crítica da modernidade. Petrópolis: Vozes, 1995. . O que é a democracia. Petrópolis: Vozes, 1996. . Poderemos viver juntos? Iguais e diferentes. Petrópolis: Vozes, 1999. 